\title{
EVALUATION OF ECOLOGICAL CONSTRUCTION IN KUNMING USING THE DPSIR MODEL
}

\author{
Chunhong Xia ${ }^{1}$, Yan $\mathrm{Li}^{1 *}$ \\ ${ }^{1}$ School of Architecture and Urban Planning, Yunnan University, 650000, China
}

(Received: July 2018 / Revised: August 2018 / Accepted: December 2018)

\begin{abstract}
Kunming is located in the south-western part of China and a lakeside city situated on plateau. Its ecological construction is typically representative. This paper takes the ecological construction data of Kunming City from 2007 to 2016 as a sample, and uses the Driving ForcePressure-State-Influence-Response (DPSIR) model to quantitatively analyze the date, aiming at an objective evaluation of the future ecological construction of Kunming. The urban road greening proposes practical measures. The results of research show that in the past ten years, Kunming's ecological construction has shown a "fast-slow-stable" upward trend, indicating that it has achieved remarkable results. In the future, importance will continue to be attached to the development of tertiary industry, focusing on the introduction of innovative talents, and encouraging the active participation of the citizens. This is the "three-horse carriage", which means three horses pull the cart together, for the sustainable development of ecological construction in Kunming.
\end{abstract}

Keywords: $\quad$ DPSIR model; Ecological construction; Index evaluation; Kunming City

\section{INTRODUCTION}

As the global urbanization process continues to accelerate, the urban economy has developed rapidly, but this has also brought a series of environmental problems, such as air pollution, noise pollution, the greenhouse effect, and excessive occupation of farmland. After paying attention to how the urban ecological environment is protected and constructed, researchers are now focusing on evaluation of ecological environment measurement. At present, Chinese research mainly centers on two aspects. First, it evaluates the relationship between the ecological environment and urbanization, drawing on foreign research results, and conducting empirical tests on the scientific and sustainable development of the environmental Kuznets curve. Scholars generally use per capita GDP and "industrial three wastes" as indicators, and use multi-year sequence data to conduct empirical research on national, provincial, and prefecture-level city scales, together with the results of the research and environmental Kuznets curve. Consistent (Wenyan, 1994; Du, 1994; Yaochen \& Bingdong, 1997; Guohua et al., 2017), further verifying the adaptability of the environmental Kuznets curve in China. The order is universal, and also shows that most of China's regions are still in an extensive development mode, with economic growth intensifying the pressure on the ecological environment. Scholars are also further enriching the theory of sustainable development (Gao et al., 1999; Zhu, 2000; Manhong, 2003), based on the continuous evaluation and application of sustainable development models, and constantly improving the evaluation index system of sustainable development from multiple perspectives (Jin-sheng et al., 2017; Huang, 2013; Guo, 2017;

*Corresponding author's email: Leeyan5@163.com, Tel. +86-0871-65930635, Fax. +86-0871-65930635

Permalink/DOI: https://doi.org/10.14716/ijtech.v9i7.2489 
Yaochen \& Bingdong, 1997; Xia \& Zhengnan, 2013), on different scales of China. The concerned administrative unit conducts measurements to contribute to the complex relationship between population, resources, environment and sustainable development at all scales across the country, as well as the situation for sustainable development.

Located in the southwestern part of China, Kunming is the seat of the provincial capital of Yunnan Province. It plays a benchmarking role in the urban ecological construction of the province and is an important part of the construction of "Beautiful Yunnan". In the Kunming City Master Plan (2011-2020), the city has repositioned its development goals, attempting to build itself into a gateway city based in southwest of China, and an important regional national transportation and information hub, making Kunming a melting pot, a culturally livable city with a history of humanities and natural scenery. In this paper, a set of evaluation index systems of ecological construction in Kunming is designed by the DPSIR model. The entropy weight method, AHP and linear weighting method are used to quantitatively measure the ecological construction of the city. Through the evaluation system, an objective analysis of the ten-year construction of Kunming eco-city is attempted to identify the advantages and disadvantages, and improve its inadequacies, making it a green city with ecological, tourism-economic integration.

\section{METHODS}

First, based on the DSPIR model, and combined with the situation of Kunming, the corresponding indicators were selected to construct a corresponding evaluation index system. Second, weight assignment was performed, but since the different indicators have different attributes, the data must first be dimensionless. Finally, the ecological construction of Kunming City from 2007 to 2016 was scored by using the linear weighting method formula.

\subsection{Progress of the Calculation}

This was first proposed by the Organisation for Economic Co-operation and Development (OECD) in the 1990s, and later developed by the European Environmental Agency (EEA). It is an effective tool for identifying causality between state and environmental issues. The model aims to conduct a multi-dimensional analysis of the relationship between ecological construction in a region and the overall environmental development prospects, ensuring that policies that are realistic and easy to implement are developed at each stage. Secondary is the standardization of the data. The data were non-dimensionalized using the extreme value method. The formula used is:

Positive indicator standardization:

$$
D s t=\frac{X_{s t}-X_{s t \text { min }}}{X_{t \text { max }}-X_{t \text { min }}}
$$

Negative indicator standardization:

$$
D_{s t}=\frac{X_{s t \max }-X_{s t}}{X_{t \max }-X_{t \min }}
$$

From these, the standardized index value is the original value of the index. Positive indicators are equivalent to incentives, so the greater the value of the positive indicator, the better the result. The negative indicator is equivalent to the blocking effect, so the lower the value of the negative indicator, the better. 
Next, the weight of the indicator was determined. There are many methods for the analysis of weights. They can be divided into two categories: one is subjective assignment, such as the Delphi method, which is AHP; the other is objective assignment through different types of mathematical formulas, such as principal component analysis, the Entropy weight method, and the coefficient of variation method. In order to reflect the comprehensiveness of index weights, subjective and objective assignment methods (tomographic analysis method and entropy weight method) were combined, and the average of the weights taken as the final index weight. Five specific calculation steps are involved in the Analytic Hierarchy Process (AHP): (1) establishment of a two-level hierarchical structure; (2) establishment of a two-two comparison judgment matrix, and comparison of the importance between the two according to the scale of the judgment matrix; (3) by calculation of the hierarchical factor single-sorted data, the maximum eigenvalue of the judgment matrix is calculated; (4) the consistency test is performed, and the judgment matrix can be accepted only when the consistency ratio is less than 0.1(if the condition is not satisfied, the judgment matrix needs to be corrected until it is satisfied); and (5) calculation of the average value of the feature values of the same model, that is, the weight value. An overview of the entropy weighting method is given below In information theory, uncertainty is often used to measure uncertainty. The amount of information and entropy show an inverse relationship; that is, as the amount of information that people have mastered increases, uncertainty decreases, and entropy decreases. Therefore, according to this characteristic, the degree of dispersion of the index can be judged by the entropy value; that is, the greater the degree of dispersion of the index, the greater its influence (weight) on the comprehensive evaluation. The specific calculation process is as follows:

Step 1: Calculate the proportion of the index value of the nth item under the m-th index $D_{\mathrm{mm}}$. If there are $j$ items to be assessed and $i$ evaluation indicators, they form the original evaluation matrix.

\section{Step 2:}

$$
\mathrm{R}=\left(X_{m m}\right)^{i^{*} j}
$$

$$
P_{n m}=\frac{X_{n m}^{\prime}}{\sum_{n=1}^{j} X_{n m}^{\prime}}
$$

Calculate the entropy of the m-th index $e_{m}$

$$
e_{m}=-k \sum_{n=1}^{j} P_{n m} \cdot \ln p_{n m}
$$

Step 3: Calculate the entropy weight of the m-th index $Z_{m}$

$$
Z_{m}=\left(1-e_{m}\right) / \sum_{n=1}^{i}\left(1-e_{j}\right)
$$

Finally, after determining the weight of each indicator of ecological construction in Kunming City, according to the linear weighted comprehensive scoring formula, the comprehensive score of such construction from 2007 to 2016 can be calculated:

$$
W=\sum_{i=1}^{n} W_{i j} X_{i j}^{\prime}
$$

where $W$ denotes the comprehensive score of ecological construction in Kunming every year, $W_{\mathrm{ij}}$ denotes the weight of each index, and $X^{\prime}{ }_{\mathrm{ij}}$ denotes the index data of the extreme value. 


\subsection{Evaluation Index System of Ecological Construction}

Combining Kunming's geographical location, natural resources, citizens' habits, and other specific conditions, and based on scientific, independent, goal-oriented and forward-looking principles, under the five levels of driving force, pressure, state, impact and response, 21 universal and highly-identified secondary indicators were selected, constituting the basic indicator system for the evaluation of ecological construction in Kunming, Meanwhile the comprehensive weight value of each indicator according to the weight calculation steps was calculated in order to obtain Table 1 below.

Table 1 Evaluation index system of ecological construction

\begin{tabular}{|c|c|c|c|c|c|c|}
\hline Target layer & $\begin{array}{l}\text { Criterion } \\
\text { layer }\end{array}$ & No & Indicator layer & $\begin{array}{l}\text { Entropy weight } \\
\text { method index } \\
\text { weight } \\
\end{array}$ & $\begin{array}{c}\text { Analytical } \\
\text { hierarchy } \\
\text { process weight } \\
\end{array}$ & $\begin{array}{l}\text { Final } \\
\text { weight }\end{array}$ \\
\hline \multirow{21}{*}{$\begin{array}{c}\text { Kunming } \\
\text { Ecological } \\
\text { Construction } \\
\text { Evaluation } \\
\text { Index } \\
\text { System }\end{array}$} & \multirow{5}{*}{$\begin{array}{l}\text { Driving force } \\
0.2589\end{array}$} & D1 & GDP Per Capita (Yuan) & 0.0469 & 0.0168 & 0.0319 \\
\hline & & D2 & $\begin{array}{l}\text { Urban Residents' } \\
\text { Disposable Income (Yuan) }\end{array}$ & 0.0468 & 0.0969 & 0.0718 \\
\hline & & D3 & $\begin{array}{l}\text { Tertiary Industry (Billion } \\
\text { Yuan) }\end{array}$ & 0.0448 & 0.1020 & 0.0734 \\
\hline & & D4 & $\begin{array}{l}\text { Natural Population } \\
\text { Growth Rate (\%o) }\end{array}$ & 0.0510 & 0.0166 & 0.0338 \\
\hline & & D5 & Urbanization Rate $(\%)$ & 0.0509 & 0.0450 & 0.0480 \\
\hline & \multirow{5}{*}{$\begin{array}{c}\text { Pressure } \\
0.1760\end{array}$} & $\mathrm{P} 1$ & $\begin{array}{l}\text { (Urban Per Capita Park } \\
\text { Green Area (Square } \\
\text { Meter) }\end{array}$ & 0.0502 & 0.0479 & 0.0491 \\
\hline & & $\mathrm{P} 2$ & $\begin{array}{l}\text { Completed Housing Area } \\
\text { (Square Meter) }\end{array}$ & 0.0182 & 0.0157 & 0.0169 \\
\hline & & P3 & $\begin{array}{l}\text { Urban Population Density } \\
\text { (People/Square Kilometer) }\end{array}$ & 0.0510 & 0.0080 & 0.0295 \\
\hline & & $\mathrm{P} 4$ & $\begin{array}{l}\text { Crop Cultivation Area } \\
\text { (Ten Thousand Acres) }\end{array}$ & 0.0510 & 0.0303 & 0.0406 \\
\hline & & P5 & $\begin{array}{l}\text { Daily Water Consumption } \\
\text { Per Capita (L) }\end{array}$ & 0.0507 & 0.0289 & 0.0398 \\
\hline & \multirow{3}{*}{$\begin{array}{l}\text { Status } \\
0.1056\end{array}$} & $\mathrm{~S} 1$ & Built-up Area/Green Area & 0.0507 & 0.0109 & 0.0308 \\
\hline & & $\mathrm{S} 2$ & $\begin{array}{l}\text { Rate }(\%) \\
\text { Per Capita Urban Road }\end{array}$ & 0.0487 & 0.0130 & 0.0309 \\
\hline & & $\mathrm{S} 3$ & $\begin{array}{l}\text { Area (Square Meter) } \\
\text { Construction Industry } \\
\text { Added Value (Billion } \\
\text { Yuan) }\end{array}$ & 0.0424 & 0.0455 & 0.0439 \\
\hline & \multirow{4}{*}{$\begin{array}{l}\text { Influences } \\
0.1534\end{array}$} & I1 & $\begin{array}{l}\text { Environmental Noise } \\
\text { (Decibe) }\end{array}$ & 0.0511 & 0.0601 & 0.0556 \\
\hline & & $\mathrm{I} 2$ & $\begin{array}{l}\text { Excellent Air Quality } \\
\text { Days (Days) }\end{array}$ & 0.0510 & 0.0147 & 0.0329 \\
\hline & & $\mathrm{I} 3$ & Pesticide Use (Tons) & 0.0506 & 0.0085 & 0.0295 \\
\hline & & $\mathrm{I} 4$ & $\begin{array}{l}\text { Traffic Jams } \\
\text { (Ten Thousand Vehicles) }\end{array}$ & 0.0472 & 0.0236 & 0.0354 \\
\hline & \multirow{4}{*}{$\begin{array}{c}\text { Response } \\
0.3058\end{array}$} & $\mathrm{R} 1$ & $\begin{array}{l}\text { Environmental Protection } \\
\text { Investment (Ten Thousand } \\
\text { Yuan) }\end{array}$ & 0.0470 & 0.2248 & 0.1359 \\
\hline & & $\mathrm{R} 2$ & $\begin{array}{l}\text { Domestic Garbage } \\
\text { Harmless Treatment } \\
\text { Rate }(\%)\end{array}$ & 0.0509 & 0.1132 & 0.0821 \\
\hline & & $\mathrm{R} 3$ & $\begin{array}{l}\text { Green Coverage } \\
\text { Area(Hectares) }\end{array}$ & 0.0509 & 0.0502 & 0.0506 \\
\hline & & $\mathrm{R} 4$ & $\begin{array}{l}\text { R\&D Total Staff } \\
\text { ( People ) }\end{array}$ & 0.0480 & 0.0267 & 0.0373 \\
\hline
\end{tabular}

Note: The table is rounded to four digits after the decimal point, so the weights at the various levels deviate slightly from the actual values, but these are used in the actual calculation. 


\section{RESULTS AND DISCUSSION}

\subsection{System Performance Results}

After determining the weight of each indicator of ecological construction in Kunming City according to the linear weighted comprehensive scoring formula, the comprehensive score of ecological construction of Kunming City from 2007 to 2016 can be calculated, as show in Figure 1.

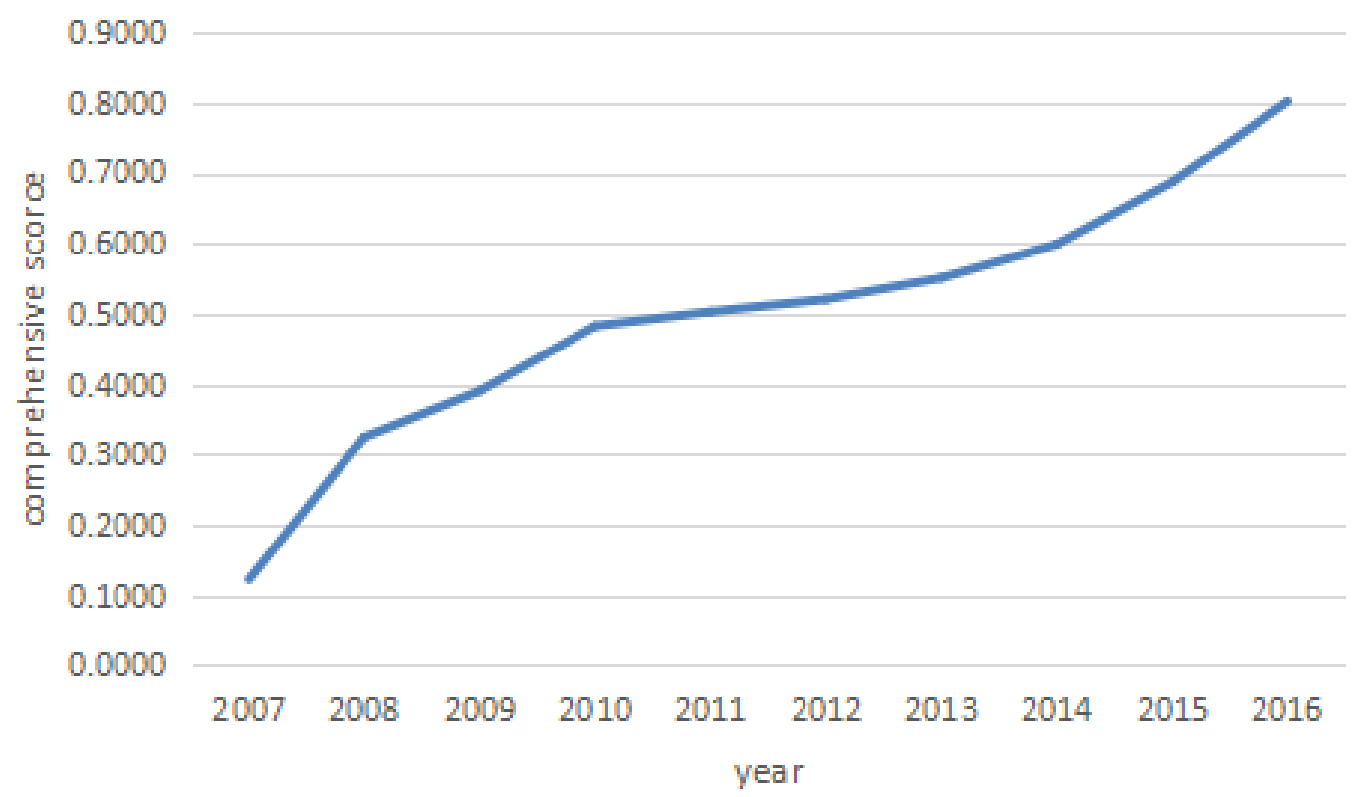

Figure 1 Comprehensive score in figure of ecological construction in Kunming

\subsection{Data Analysis}

The above data reflect the intrinsic link between various indicators of ecological construction in Kunming during the ten years from 2007 to 2016. At the same time, the dynamic changes in the comprehensive level of ecological construction in the city can be clearly seen. Through chart analysis, the following conclusions can be drawn:

1. In 2007-2016, the level of ecological construction in Kunming City generally showed an upward trend. The highest year for the ecological construction index was 2016, reaching 0.8017, and the lowest year was 2007, 0.1224. However, the scores of the indicators for each year are positive, indicating that Kunming City attaches great importance to the construction of the "ecological block" and has achieved remarkable results.

2. The growth rate of ecological construction in Kunming is not balanced, showing an upward trend of "quick-slow-smooth". Through the line chart, we can clearly see that from 2007 to 2010, the ecological construction score rose from 0.1224 to 0.4823 , an increase of $294 \%$, and is therefore a rapid growth period; the 2010-2013 ecological construction score rose from 0.4832 to 0.5507 , an increase of $14.18 \%$, so belonging to as low growth period. From 2013 to 2016, the rate of increase from 0.5507 to 0.8017 in the three years was $45.58 \%$. Although this was far ahead of the ecological construction speed in the previous three years, the growth rate was relatively low compared to 2007-2010 and represented a stage of steady growth.

3. In the urban ecological construction of Kunming, economic factors as the main driving force, and government environmental protection measures as a positive response are closely related to these. The driving force (index weight: 0.2359$)$ and response $(0.3058)$ are ranked the top two out of the five criterion levels. Kunming City is located in the border area of 
southwest China. Restricted by locational conditions, Kunming should pay attention to the development of regional economy, especially the tertiary industry, to protect natural resources. Importance must be attached to the development of the regional economy. Tertiary industry (index weight 0.0734 ) is the pillar industy. In addition, it is worth noting that the achievements made by Kunming's ecological construction largely depend on the government's huge investment in environmental protection (index weight 0.1359 ).

\subsection{Suggestions}

\subsubsection{Continued emphasis on the development of tertiary industry based on tourism}

Kunming is dominated by Plateau Mountains, which are ecologically fragile, and have insufficient environmental carrying capacity. If heavy industry is developed, Dian Chi will suffer serious damage and air pollution will threaten the health of Kunming citizens. Therefore, tertiary industry is the "power carriage" of economic development in the city. The unique ethnic minority culture, the spring season climate and the pleasant natural scenery provide unique natural and cultural conditions for the development of tourism in Kunming. To develop the tourism industry, the spatial pattern of "one heart, one belt, two rings, three and five lines" needs to be adhered to develop the Yangzonghai provincial-level scenic spots, Shilin nationallevel scenic spots, and Kunming urban ethnic minority villages. The local governments should develop and utilize tourism resources rationally. At the same time, full play should be given to the advantages of location-oriented gateway cities in Southeast Asia and South Asia, with active integration of the "One Belt and One Road" initiative to accelerate the construction of the Langzhong Economic Circle and attract more foreign investors and tourists to drive the development of Kunming and even the entire province. The ecological construction of the area provides sufficient capital and resources for creating a livable lakeside city on the plateau.

\subsubsection{Encourage the development of innovative enterprises and attract high-tech talents to settle in the area}

Innovation is the companies' core competitiveness, the "motor" of social progress and the source of national progress. On one hand, the Kunming municipal government can make full use of the natural advantages of Spring City, promulgate a series of policies that encourages the entry of innovative enterprises and talents to enter the region, and encourage talented people from different areas to go to Kunming. On the other hand, combined with Kunming's unique resources, the local green environmental protection industry should be supported, and given taxation, funding and other preferential support. At the same time, it is necessary to attach importance to the industrial layout and expected development plan of the Chenggong New District and Konggang New District, and to focus on the three major sectors of ecological industries, high-tech industries, and new industrial parks. Heavy industry enterprises and energy-consuming enterprises should be forbidden from entering. In addition, local colleges and universities should also pay attention to cultivating innovative talents and retaining talented, ideologically and technologically outstanding graduates through the "introduction of talents."

\subsubsection{Strengthen citizens' urban ecological awareness and advocate a green and low-carbon life}

China's development has entered a new era. The role of the government should be adjusted and gradually changed from that of "commander" to "participant". In the treatment of public affairs, the government is gradually changing from public management to public governance; in the formulation of public policy, the government is changing from "command type" to "consultative" decision-making. This kind of change also requires the citizens to change their roles, from being "bystanders" to the main body of urban ecological construction management, to cultivating urban ecological awareness, actively participating in various actions to enhance the city's image and improve the quality of life in the city. They should respond to green and low carbon life initiatives, which promote green development with the concept of low-carbon 
consumption, guiding urban planning blueprints with the concept of green ecology, educating the next generation with awareness of environmental protection and energy conservation, and encouraging social innovation with the concept of smart environmental protection.

\section{CONCLUSION}

Through the assessment of the ecological construction of Kunming City over ten years, inadequacies have been found; for example, excessive dependence on the government's environmental protection funds and lack of ecological technology investment. Moreover,the potential value of enterprises, non-profit organizations, individuals and technology in ecological construction has not been fully explored. Therefore, in the process of ecological construction in the future, the government should transform the "ecologically-oriented approach" into "ecological cooperation approach", cultivating technical talents, and using environmental technology to develop ecological industries. This article has drawn lessons from the formulation and development of policies in governmental environmental protection work.

\section{ACKNOWLEDGEMENT}

This research would not have been possible without the contributions of several people and organizations. To all of these, I wish to express my gratitude. First and foremost, I would like to acknowledge and extend my heartfelt gratitude to my supervisor, Associate Professor Yan Li, for her vital encouragement and patient guidance, generous assistance and invaluable advice, all of which have been of inestimable worth to the completion of this research.

Second, my special thanks go to all the institutes that gave me authoritative data which confirmed the results of the study, namely the Government Statistics Bureau and Yunnan Provincial Library.

\section{REFERENCES}

Du, Z., 1994. China's Agenda 21 and Geography. Acta Geographica Sinica, Volume 49, pp. 481-487

Gao, Z.Q., Liu, J., Fang, Z.D., 1999. Relationship between the Ecological Environment Quality of China's Land Resources and Population Distribution based on Remote Sensing and GIS. Journal of Remote Sensing, Volume 1, pp. 66-70

Guo, Y., 2017. Evaluation of Ecological Civilization Construction of Chengdu-Chongqing Urban Agglomeration. China: Chengdu University of Technology

Guohua, B., Qingyuan, Y., Su, L., 2017. Coupling Coordination Development between Ecological Civilization Construction and Urbanization in China. Economic Geography, Volume 37, pp. 51-58

Huang, X., 2013. Evaluation and Prediction of Urban Ecological Civilization Construction in Central Guizhou. China: Kunming University of Science and Technology

Jin-sheng, F., Yong-lan, Z., Liang, X., 2017. The Construction of Evaluation Index System of Ecological Civilization Towns in Chizhou City. Journal of Anhui Agricultural Sciences, Volume 14, pp. 34-37

Manhong, S., 2003. A Summary of the National Symposium on the Theory and Practice of Ecological Economic Construction. Journal of Economics, Volume 4, pp. 45-46

Wenyan, L., 1994. Sustainable Development and Geography. Journal of Geographical Sciences, Volume 49, pp. 97-106

Xia, Z., Zhengnan, L., 2013. Evaluation of Low Carbon City Development based on DPSIR Model - - Taking Jiangsu Province as an Example. Technology Economics and Management Research, Volume 15, pp. 46-51 
Yaochen, Q., Bingdong, Z., 1997. Simulation and Control of System Dynamics in Sustainable Development of Henan Province. Systems Engineering and Practice, Volume 7, pp. 124131

Zhu, N.W.Y., 2000. Introduction to Sustainable Development (Chinese Edition). Science Press, pp. 28-29 